\title{
A Case Report: Solitary Plasmacytoma of bone (SPB) Presenting as an Incidentaloma in a COVID-19 Positive Patient
}

\author{
Shastry ${ }^{1 *}$, Singla $\mathrm{A}^{2}$, Chandel $\mathrm{U}^{3}$
}

${ }^{1}$ Department of Pathology, ${ }^{2}$ Department of Radiology, ${ }^{3}$ Department of Medicine, NR Hospital, Bilaspur, Himachal Pradesh, India

DOI: $\underline{10.36347 / \text { sjmcr.2022.v10i01.005 }}$

| Received: 07.12.2021 | Accepted: 12.01.2022 | Published: 16.01.2022

*Corresponding author: Shastry

Department of Pathology, NR Hospital, Bilaspur, Himachal Pradesh

\section{Abstract}

A 70-yr-old covid positive male patient who presented with cough and shortness of breath, upon CT chest found to have features typical of COVID-19 infection and a small mass arising in left 8th rib. A histopathological examination of the mass found to be osseous plasmacytoma, after a PET scan it was confirmed to be a solitary lesion. Bone marrow aspiration cytology showed normal plasma cell count, thus, diagnosed as solitary Plasmacytoma of bone. There was no negative impact on the recovery of the patient by COVID-19 due to solitary Plasmacytoma.

Keywords: Solitary Plasmacytoma, Osseous plasmacytoma, COVID-19, Multiple Myeloma.

Copyright $(\mathcal{C} 2022$ The Author(s): This is an open-access article distributed under the terms of the Creative Commons Attribution 4.0 International License (CC BY-NC 4.0) which permits unrestricted use, distribution, and reproduction in any medium for non-commercial use provided the original author and source are credited.

\section{INTRODUCTION}

Plasmacytoma is a plasma cell dyscrasia in which monoclonal plasma cells accumulate in certain parts of the body. When it arises from a bone, it is called osseous plasmacytoma and when it is seen in soft tissue it is called extra-osseous or extramedullary plasmacytoma. This entity is considered as a spectrum in the manifestation of plasma cell neoplasm where it can progress to a more aggressive Multiple Myeloma [1]. It involves the bones which are actively involved in hematopoiesis, like vertebrae, ribs, and skull in the order of occurrence [2]. It is uncommon in long bones and in the bones below the elbow and knee [3]. Clinically presents as pain at the site of involvement, in the vertebrae it can cause fracture and spinal compression due to osteolysis. SBP has a high risk for progression into multiple myeloma as it arises from plasma cells in the bone marrow. The risk is approximately $64-85 \%$ in 10 years $[2,3]$.

The present case is an unusual presentation as an incidentaloma in a covid-19 patient. There was no impact on the recovery of the patient from SARS-COV2 infection due to plasmacytoma.

\section{CASE REPORT}

A 70-yr-old male patient with cough and shortness of breath on covid -19 antigen testing by immunoassay tested positive. Before sending the patient to a covid care facility a CT scan of the chest was done to assess the severity. On CT scan lungs showed ground glass opacities with predominant posterior and peripheral distribution with extensive involvement of the lower lobes, without consolidation, no pleural effusion and no pneumothorax. Prominent lymph nodes in the right and left paratracheal area and subcarinal areas noted. Patient was also found to have a $3 \times 2 \mathrm{~cm}$ enhancing soft tissue lesion in the left lateral 8th rib with smooth margins and erosion of the inner cortex (figure 1).

In-house investigations were kept minimal since the patient had SARS-COV-2 infection. His Urea, creatinine, uric acid, PT, APTT were within normal limits. Biopsy of the mass was taken for a histopathological examination and the patient was referred to a COVID care facility.

Five linear bits of core needle biopsy were received, longest measured $1.2 \mathrm{~cm}$ in length. The sections were stained with haematoxylin and eosin for a light microscopic examination (figure 2). It showed sheets of mature plasma cells with eccentric nuclei with distinct chromatin condensation, and immature plasma cells with prominent nucleoli and nuclear pleomorphism, as shown in the figure 2, image C. Also arranged in chords and single file pattern separated by fibrocollagenous stroma. No bone marrow tissue was present in the sections. A piece of lung tissue present in the sections showed normal histology with mild interstitial expansion consisting of lymphocytes. There 
were no features suggestive of COVID-19 induced lung inflammation. Thus a diagnosis of Osseous Plasmacytoma was made with a recommendation for IHC markers to confirm the diagnosis and to rule out lymphomas with plasmacytoid features. Also, the patient was advised for a bone scan to identify lytic bone lesions elsewhere in the body, bone marrow aspiration cytology, and serum M-protein level to rule out Multiple Myeloma.
After recovering from COVID-19, patient got a 18 F-FDG PET-CT SCAN which confirmed the presence of lytic bone lesion in the posterior-lateral aspect of left 8th rib and there was no evidence of any other hyper-metabolic osteolytic/osteosclerotic lesion in the skeletal system. A bone marrow aspiration cytology concluded normal plasma cell count. Since the patient could not afford IHC markers, diagnosis was concluded as solitary Plasmacytoma of bone.
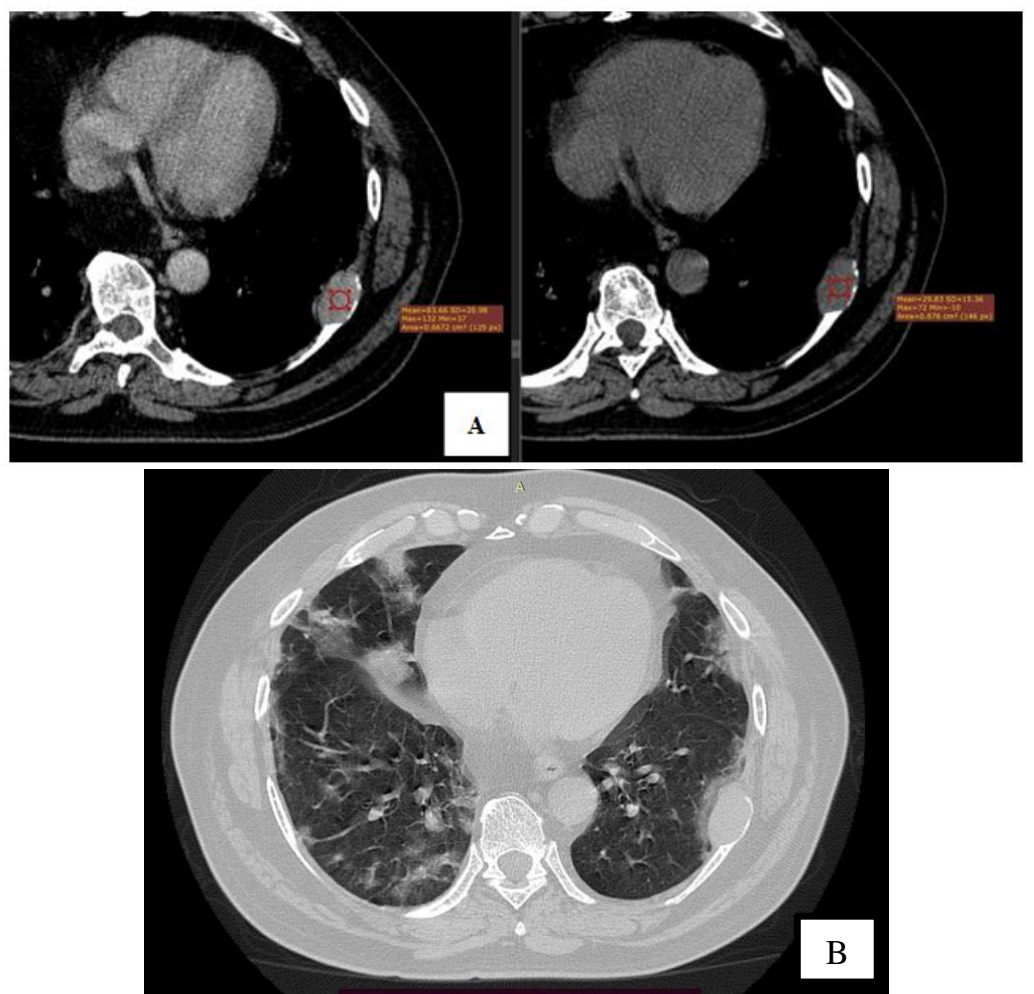

Fig-1: CT chest. A. Plain CT shows a mass arising in the posterior lateral part of the 8th rib, enlarged lymph nodes in the paratracheal area, ground glass opacities with predominant posterior and peripheral distribution. B. Contrast enhanced CT shows a lyric bone mass with cortical expansion.
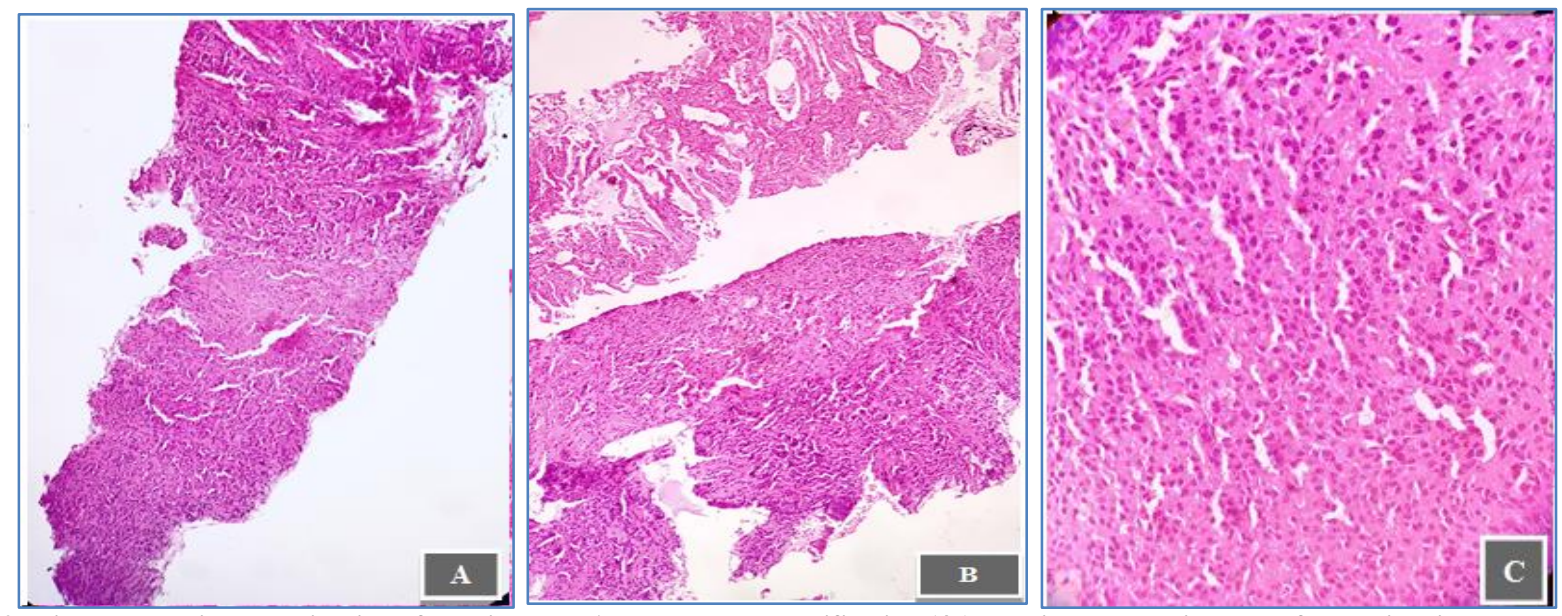

Fig-2: Histopathological examination of the rib mass. A.Low power magnification $(4 x)$ showing the architecture of the lesion, in sheets and in chords. B. Low power $(\mathbf{4 x})$ shows lung tissue with mild fibrosis and lymphocytic infiltration in the interstitium. The adjacent bit of tissue shows sheets of plasma cells surrounded by fibrous tissue. C. High power (40X) shows sheets of plasma cells with characteristic nuclear clumping and eccentrically placed nuclei with cytoplasmic vacoulations. 


\section{DiSCUSSION}

Males around the age of 65 with symptoms of localized back pain with or without bone fracture and spinal cord compression is a typical pattern of presentation for solitary plasmacytoma of the bone (SPB), as found in the majority of studies [4-6]. SPB in itself is a rare localized monoclonal disease of the plasma cells of the bone marrow. Diagnostic criteria for SPB are a solitary skeletal lesion confirmed by complete skeletal survey, biopsy proven clonal proliferation of the plasma cells, absence of end organ damage related to multiple myeloma like kidney failure, bone marrow plasma cell population of less than $10 \%$ [2]. However, patients can have some amount of ' $M$ ' protein in the serum but not more than $3 \mathrm{~g} / \mathrm{dL}$ [1]. Thus, a comprehensive body examination is required for the diagnosis of the lesion. Durie and Salmon [7] consider solitary Plasmacytoma of the bone as a stage-1 myeloma.

Radiographic features of the SBP usually show a well-defined expansile osteolytic lesion with cortical destruction, with absence of sclerotic reaction on a CT scan sometimes referred to as 'mini-brain' lesion in vertebra. This characteristic appearance can also be appreciated on an MRI, where curvilinear low signal intensity areas within the lesion gives the appearance of cerebrum [8]. On plain X-ray it can show soap bubbles/trabeculations [9].

According to Shen et al, a study conducted in the USA showed a median survival of 88 months in the population of the 21 st century, with an outcome of development of multiple myeloma [10]. Prognostic factors which determine the risk of progression to multiple myeloma are, lesions $>5 \mathrm{~cm}$ in size, more than 40 years of age group, vertebral lesions, high ' $\mathrm{M}$ ' protein levels and persistence of ' $\mathrm{M}$ ' protein after treatment $[1,11,12]$. However, the prediction of the progression to multiple myeloma is still unclear [13].

Treatment for the plasmacytoma is radiotherapy. Surgical excision and decompression is required in cases with spinal compression. In spite of the treatment, risk for progression to multiple myeloma is $65-84 \%$ in 10 years [11].

\section{In CONCLUSION}

An incidental osseous Plasmacytoma was found in a rib in a covid patient with CO-RADS classification 5 and CT severity score of $10 / 25$, which was later confirmed to be solitary without increase in plasma cells in the bone marrow. There was no impact on patient recovery from COVID-19 infection.

\section{Learning points}

- SPB most commonly involve vertebrae and present as painful bone lesions with or without fracture, or spinal cord compression. But, it can also arise in other flat bones.

- It is uncommon to find SPB as an incidental finding.

- Multiple Myeloma has to be ruled out in all the patients presenting as solitary osseous plasmacytoma, since the lesion arises from plasma cells of the bone marrow.

- Only $80 \%$ of the patients with multiple myeloma present with lytic bone lesions at the point of initial diagnosis.

- Absence of lytic bone lesions does not exclude the presence of multiple myeloma.

- All the patients with a diagnosis of osseous plasmacytoma should be advised to undergo radiological workup, kidney function tests, serum $\mathrm{M}$ protein levels and a bone marrow aspiration cytology for an early detection of multiple myeloma.

\section{Conflicts of interest}

Authors declare that there is no conflict of interests in the publication of this paper.

\section{REFERENCES}

1. Kumar, V., Abbas, A. K., \& Aster, J. C. (2021). Chapter 13, diseases of white blood cells, lymph nodes, spleen and thymus. Robbins and Cotran pathologic basis of disease (Tenth edition.). Philadelphia, PA: Elsevier/Saunders.

2. Saksena, A., Mahajan, N., Agarwal, S., \& Jain, S. (2014). Solitary bone plasmacytoma: An interesting case report with unusual clinicocytological features. Journal of Cytology/Indian Academy of Cytologists, 31(3), 158.

3. Kanthan, R., \& Torkian, B. (2003). Solitary plasmacytoma of the parotid gland with crystalline inclusions: A case report. World journal of surgical oncology, 1(1), 1-6.

4. Agbuduwe, C., Yang, H., Gaglani, J., \& Ajithkumar, T. (2020). Clinical presentation and outcomes of solitary plasmacytoma in a tertiary hospital in the UK. Clinical Medicine, 20(5), e191.

5. de Waal, E. G., Leene, M., Veeger, N., Vos, H. J., Ong, F., Smit, W. G., ... \& Vellenga, E. (2016). Progression of a solitary plasmacytoma to multiple myeloma. A population-based registry of the northern Netherlands. British journal of haematology, 175(4), 661-667.

6. Ozsahin, M., Tsang, R. W., Poortmans, P., Belkacémi, Y., Bolla, M., Dinçbas, F. Ö., ... \& Zouhair, A. (2006). Outcomes and patterns of failure in solitary plasmacytoma: a multicenter Rare Cancer Network study of 258 patients. International Journal of Radiation Oncology* Biology* Physics, 64(1), 210-217.

7. Fechtner, K., Hillengass, J., Delorme, S., Heiss, C., Neben, K., Goldschmidt, H., ... \& Weber, M. A. (2010). Staging monoclonal plasma cell disease: comparison of the Durie-Salmon and the Durie- 
Salmon PLUS staging systems. Radiology, 257(1), 195-204.

8. Di, Muzio, B., Ibrahim, D. Solitary bone plasmacytoma. Reference article, Radiopaedia.org. https://doi.org/10.53347/rID-12539

9. Das, S., Yanamandra, U., Iqbal, S., \& Kapoor, R. (2019). Multiple myeloma mimicking primary bone tumour. BMJ case reports, 12(10).

10. Yurac, R., Silva, A., Delgado, M., Nuñez, M., Lopez, J., \& Marre, B. (2021). Pathological axis fracture secondary to a solitary bone plasmacytoma: Two cases and a literature review. Surgical Neurology International, 12.
11. Kilciksiz, S., Karakoyun-Celik, O., Agaoglu, F. Y., \& Haydaroglu, A. (2012). A review for solitary plasmacytoma of bone and extramedullary plasmacytoma. The Scientific World Journal, 2012.

12. Siddaraju, N., Basu, D., \& Soundararaghavan, J. (2007). Use of fine needle aspiration cytology in the diagnosis of extraosseous plasmacytoma presenting with monoclonal gammopathy: A case report. American Journal of Case Reports, 8, 9093.

13. Bataille, R., \& Sany, J. (1981). Solitary myeloma: clinical and prognostic features of a review of 114 cases. Cancer, 48(3), 845-851. 